\title{
Antioxidant and Postprandial Glucose-lowering Potential of the Hydroethanolic Extract of Nypa fruticans Seed Mesocarp
}

Fonkoua Martin ${ }^{1}$, Nguimkeng Signing Boris' ${ }^{1}$, Sandeu Ruth Kengne ${ }^{1}$, Tang Eramus Chia, Takuissu Nguemto Guy, Azantsa Kingue Boris Gabin, J. L. Ngondi1,*, Gouado Innocent ${ }^{2}$

${ }^{1}$ Department of Biochemistry, Faculty of Science, University of Yaounde I, Yaounde, Cameroon

${ }^{2}$ Department of Biochemistry, Faculty of Science, University of Douala, Douala, Cameroon

*Corresponding author: Ngondi JL, Department of Biochemistry, Faculty of Science, University of Yaounde I, Yaounde, Cameroon; E-mail: ngondijudithı@hotmail.com Received: Jun 5, 2017; Accepted: Jul 07, 2017; Published: Jul 14, 2017

Copyright: @ 2017 Martin et al. This is an open-access article distributed under the terms of the Creative Commons Attribution License, which permits unrestricted use, distribution, and reproduction in any medium, provided the original author and source are credited.

\begin{abstract}
Postprandial hyperglycemia and oxidative stress are implicated in the pathophysiology of type 2 diabetes. An alternative treatment should target both conditions. The present study aimed to evaluate the antioxidant and postprandial glucose-lowering potential of a polyphenolic rich extract of Nypa fruticans nuts. Hydroethanolic extract (HEE) was prepared; polyphenol and flavonoid content was determined. In vitro antioxidant activity was done through molybdenum (VI) reduction and ABTS and DPPH radical-scavenging capacities. The glucose-lowering potential of the extract was evaluated through in vitro glucose-binding capacity, the regulatory ability of the extract on the pancreas of normal Wistar rats (oral glucose tolerance test), and digestion of carbohydrates (starch and sucrose) by normal Wistar rats. Starch $(1 \mathrm{~g} / \mathrm{kg}$ of the body weight (BW) and sucrose $(2 \mathrm{~g} / \mathrm{kg} \mathrm{BW})$ solution were used as substrates for alpha amylase and invertase inhibition test, respectively. Acarbose $(3 \mathrm{mg} / \mathrm{kg} \mathrm{BW})$ was used as the reference. Polyphenolic-rich extract $(400 \mathrm{mg} / \mathrm{kg} \mathrm{BW})$ was administered to treated rats. Results showed that HEE of $N$. fruticans nuts has antioxidant activity through the scavenging of ABTS $\left(\mathrm{EC}_{50}\right.$ of $\left.1.75 \mathrm{mg} / \mathrm{mL}\right)$ and $\mathrm{DPPH}(2.96 \mathrm{mg} / \mathrm{mL})$ radicals and the reduction of Mo (VI). The extract significantly reduced glucose concentrations at $t_{30}$ compared to glibenclamide, but glibenclamide maintained lower glycemia than the extract thereafter to the end of the study. From the administration of sucrose, the extract maintained lower plasma glucose levels compared to acarbose throughout the study. However, no inhibition was observed in glycemia following starch administration in HEE-treated group as glycemia remained higher compared to the acarbose group throughout the study. Thus, $N$. fruticans seed mesocarp is a rich source of dietary polyphenols with a strong antioxidant capacity. Its HEE has glucose-lowering potential and possible inhibitory action on the last phase of carbohydrate digestion.
\end{abstract}

Keywords: Postprandial hyperglycemia; Glucose-binding potential; Glycemic reduction; Nypa fruticans mesocarp

\section{Introduction}

Diabetes is a metabolic disorder characterized by chronic hyperglycemia. Extended postprandial hyperglycemia and high fasting plasma glucose levels are the major determinants of diabetes. High fasting plasma glucose is caused by increased hepatic release of glucose and the inability of peripheral cells to absorb the glucose, linked to insulin deficiency and insensitivity. This results in disturbances in carbohydrate, fat, and protein metabolism. Postprandial hyperglycemia results from the persistent and extended increase in plasma glucose and depends on the digestibility of carbohydrates and the regulatory capacity of pancreatic cells. Postprandial hyperglycemia leads to protein glycation and glucose oxidation, releasing oxygen and nitrogen reactive species. Oxidative stress is known to play a significant role in the development and progression of diabetes mellitus (DM). Free radicals from oxygen (reactive oxygen species (ROS)) and nitrogen (reactive nitrogen species (RNS)) are produced in the internal membrane of the mitochondria, in the endothelial vascular cells, and in the endoplasmic reticulum during auto-oxidation involving physiological molecules like NADH, NADPH, and neurotransmitters. ROS at low or moderate concentrations in human tissues are required for optimum cellular functioning but when produced in excess, they lead to cell and tissue injury. The damage caused by surplus free radicals in tissues is referred to as oxidative stress. Oxidative stress aggravates type $2 \mathrm{DM}$ [1]. The incidence and prevalence of diabetes is on a global rise and is alarming in sub-Saharan Africa and Southeast Asia [2] which are resource-scarce regions of the world. To face this pandemic, promising control strategies target diet, lifestyle, and carbohydrate metabolism. Diet and lifestyle modifications are considered the cornerstone for the treatment and management of type 2 diabetes. In addition to diet and lifestyle, pharmaceutical molecules including sulfonylureas (which stimulate insulin release) and carbohydrate enzyme inhibitors, like acarbose and miglitol, are used in monitoring type-2 DM. These drugs mainly aim at reducing postprandial upsurge in blood glucose level or delaying glucose release into the bloodstream, thereby modulating glycemia. Evidence holds that the way forward for a better monitoring of DM should target natural carbohydrate inhibitors [3] and natural antioxidants [4], which present little or no deleterious effects compared to the synthetic pharmaceutical molecules. Many plant antioxidants have hypoglycemic effects, which may also contribute to improved glycemia. Plant foods (fruits, spices, and vegetables) are important dietary sources of antioxidant polyphenols to humans. Several plant preparations are traditionally used in Cameroon to treat diabetes. Some of them have been screened for bioactivity of crude extract, but only few studies report on Nypa fruticans seed mesocarps. N. fruticans is one of such plants.

$N$. fruticans is a tropical mangrove plant of the family of Palmae/ Arecaceae whose leaves, stems, and roots have been traditionally used in the treatment of asthma, leprosy, tuberculosis, sore throat, liver disease, and snake bite, as a sedative and carminative [5]. The fruit is also rich in carbohydrates, fibers, minerals, and vitamin A [6]. The hexane, ethyl acetate, and methanolic extract of its leaves and fruits showed in vitro 
Citation: Martin F, Boris NS, Kengne SR, Chia TE, Guy TN, et al. (2017) Antioxidant and Postprandial Glucose-lowering Potential of the Hydroethanolic Extract of Nypa fruticans Seed Mesocarp. Biol Med (Aligarh) 9: 407. doi: 10.4172/0974-8369.1000407

Page 2 of 6

antioxidant activity [7], while the methanolic extract of its leaves and stem showed antihyperglycemic activity in mice [8]. This work seeks to investigate the in vitro and in vivo potency of the hydroethanolic extract (HEE) of $N$. fruticans seed mesocarp to lower blood glucose level.

\section{Materials and Methods}

\section{Chemical reagents}

All chemicals used were of analytical grade. Folin-Ciocalteu reagent, gallic acid, $\mathrm{AlCl}_{3}$, potassium acetate, cyanidic acid, ethanol, vanillin, hydrochloric acid, 1,1-diphenyl-2-picrylhydrazyl (DPPH), 2,2'-azinobis-(3-ethylbenzothiazoline 6-sulfonic acid) (ABTS), $\mathrm{KMnO}_{4}$, phosphate buffer, sulfuric acid, sodium phosphate, ammonium molybdate, glucose, glucose test kit, starch, and sucrose were purchased from SIGMA (USA).

\section{Plant collection and preparation of extracts}

Fresh $N$. fruticans fruits were harvested in the Littoral Region of Cameroon in January 2015 and together with the stems and bark of the tree were authenticated at the National Herbarium in Yaounde (Voucher $\mathrm{N}^{\circ} 38371 / \mathrm{HNC}$ ). The fruits were washed with running water. The outer layer was removed and the seed mesocarp recovered for subsequent use. The mesocarps were then air-dried in the shade (room temperature) for five days and the dried matter was ground to powder using a small scale grinding machine.

\section{Preparation of the HEE of $\mathrm{N}$. fruticans mesocarp}

To get the polyphenol rich extract, $500 \mathrm{~g}$ of $N$. fruticans mesocarp powder was macerated in $4000 \mathrm{~mL}(1 / 8)$ of water and $95 \%$ ethanol mixture (1:1). The filtrate was evaporated at $50^{\circ} \mathrm{C}$ in an oven and the yield for extraction was calculated (10\%).

\section{Determination of polyphenol and flavonoid content}

\section{Polyphenol content}

Polyphenol content was evaluated on the basis of the residue's capacity to reduce phosphomolybdic phosphor-tungstic acid (FolinCiocalteu) reagent to a blue-colored complex in an alkaline solution [9]. The measurement was done using the Folin-Ciocalteu reagent (Sigma Chemical Co. St. Louis, MO) diluted 10 times before use. Briefly, $30 \mu \mathrm{L}$ of $1 \mathrm{mg} / \mathrm{mL}$ of the extract and $1 \mathrm{~mL}$ of diluted Folin-Ciocalteu reagent were pipetted into a tube and incubated for exactly $30 \mathrm{~min}$. Parallel to the Nypa extract tubes were the $30-\mu \mathrm{L}$ catechin standard tube and the blank tube containing $30 \mu \mathrm{L}$ of distilled water. Absorbance was read at $750 \mathrm{~nm}$ in a UV spectrophotometer. Total polyphenol was expressed in milligram equivalents of gallic acid per gram of dry mesocarp powder (mg EG/g DM).

\section{Total flavonoids}

Total flavonoid content was evaluated using the method described by Aiyegoro and Okoh [10]. The method is based on the fact that flavonoids react with aluminum chloride and potassium acetate to form a pink solution whose absorbance can be measured at a wavelength of $420 \mathrm{~nm}$. Briefly, $1 \mathrm{~mL}$ of the extract $(1 \mathrm{mg} / \mathrm{mL})$ was mixed with $3 \mathrm{~mL}$ of ethanol (95\%), $0.2 \mathrm{~mL}$ of $10 \%$ aluminum chloride, $0.2 \mathrm{~mL}$ of $1 \mathrm{M}$ potassium acetate, and $5.6 \mathrm{~mL}$ of distilled water and incubated at room temperature for $30 \mathrm{~min}$. Thereafter, the absorbance was directly measured at $420 \mathrm{~nm}$ with UV visible spectrophotometer. Flavonoid content was then determined from the calibration curve prepared from catechin solution $(0-1000 \mu \mathrm{g} / \mathrm{mL})$ in distilled water. Flavonoid content was expressed in milligram equivalents of gallic acid per gram of dry mesocarp powder (mg EG/g DM).

\section{Determination of the antioxidant capacity}

\section{Total antioxidant capacity}

Total antioxidant capacity was measured using the method described by Prieto et al. [11]. This technique is based on the reduction of molybdenum (Mo VI) to Mo (V) by the test sample and the subsequent formation of a green phosphate/Mo (V) complex in acid solution with optimum absorbance at $695 \mathrm{~nm}$. A volume of $0.3 \mathrm{~mL}$ of extract $(5 \mathrm{mg} / \mathrm{mL})$ was mixed with $3 \mathrm{~mL}$ of the reagent $(0.6 \mathrm{M}$ sulfuric acid, $28 \mathrm{mM}$ sodium phosphate, and $4 \mathrm{mM}$ ammonium molybdate). All the tubes were sealed and incubated at $95^{\circ} \mathrm{C}$ for $90 \mathrm{~min}$. After cooling the tubes, the absorbance of the solutions was measured at $695 \mathrm{~nm}$ against the blank containing $3 \mathrm{~mL}$ of the reagent and $0.3 \mathrm{~mL}$ of methanol. The total antioxidant capacity was expressed in milligram equivalents of ascorbic acid per gram of dry mesocarp powder (mg EA/g DM).

\section{Free radical-scavenging activity}

The scavenging activities of the free radicals were evaluated using two synthetic radicals: 2,2'-azinobis (3-ethyl-benzothiazoline-6sulfonic acid) $\left(\mathrm{ABTS}^{+}\right)$for lipophilic and hydrophilic antioxidants and 1,1-diphenyl-2-picrylhydrazyl (DPPH•) for lipophilic antioxidants.

The DPPH radical-scavenging activity was measured according to the procedure reported by Katalinie et al. [12]. This method relies on the decrease in absorbance measured at $515 \mathrm{~nm}$, based on the capacity of the antioxidant to trap free radicals forming a stable DPPH-H. Volumes of $50 \mu \mathrm{L}$ of extracts $(2,4,6,8$ and $10 \mathrm{mg} / \mathrm{mL})$ were introduced in $1.950 \mathrm{~mL}$ of an ethanol solution of DPPH. After $30 \mathrm{~min}$ of incubation in the dark, the absorbance was measured at $515 \mathrm{~nm}$ against the blank containing the reagent.

The ABTS radical-scavenging activity was measured following a modified procedure reported by $\mathrm{Re}$ et al. [13]. In the presence of potassium permanganate $\left(\mathrm{KMnO}_{4}\right)$, blue ABTS is oxidized to green $\mathrm{ABTS}^{+}$radical. Antioxidants reduce green $\mathrm{ABTS}^{+}$radical with discoloration of the solution. Discoloration capacity measured at $734 \mathrm{~nm}$ is directly proportional to the antioxidant concentration. The extracts were prepared at different concentrations $(2,4,6,8$, and $10 \mathrm{mg} / \mathrm{mL})$ and $1 \mu \mathrm{L}$ of each concentration was put in a tube containing $1000 \mu \mathrm{L}$ of $\mathrm{ABTS}^{+}$and incubated for $30 \mathrm{~min}$ in the dark. The absorbance was read against the blank containing the reagent. The percentage inhibition of the free radical by the polyphenolic rich extract was calculated using the formula below:

$$
\text { Scavenging Capacity }(\%)=\frac{\text { Absorbance of blank-Absorbance of extract }}{\text { Absorbance of blank }} * 100
$$

The half efficient concentration $\left(\mathrm{EC}_{50}\right)$, which reflects a $50 \%$ decrease of DPPH or ABTS radical by the extract, was derived and expressed in $\mathrm{mg} / \mathrm{mL}$. $\mathrm{EC}_{50}$ was determined using the percentage scavenging capacity of all the concentrations at the stationary stage followed by the application of logarithmic regression analysis.

\section{Evaluation of the in vitro hypoglycemic activity of the extract}

Glucose-binding capacity was evaluated through the glycosylation test described by Kebieche [14]. This test is based on the ability of extracts to form complexes with free glucose, demonstrating a glucophage activity. A standard glucose solution was prepared (10 mM), from 
Citation: Martin F, Boris NS, Kengne SR, Chia TE, Guy TN, et al. (2017) Antioxidant and Postprandial Glucose-lowering Potential of the Hydroethanolic Extract of Nypa fruticans Seed Mesocarp. Biol Med (Aligarh) 9: 407. doi: 10.4172/0974-8369.1000407

Page 3 of 6

which $100 \mu \mathrm{L}$ was pipetted into seven tubes and mixed with $100 \mu \mathrm{L}$ of the polyphenol-rich extract of $N$. fruticans seed mesocarp powder at different concentrations $(0.5,1,2,4,8$, and $16 \mathrm{mg} / \mathrm{mL})$. The mixture obtained was gently homogenized and incubated at $37^{\circ} \mathrm{C}$ for $15 \mathrm{~min}$. Glucose concentration was then measured using the SGM Italia kit as described by Trinder [15] and the absorbance read at $505 \mathrm{~nm}$. A control was made in absence of the extract. The percentage of glucose binding was obtained using the following formula:

Glucose binding $(\%)=\frac{\text { Glucose of control }- \text { Glucose of extract }}{\text { Weight of sample }} \times$ Volume of solution

\section{Postprandial glucose-lowering potential in normoglycemic rats}

Adult male albino Wistar rats weighing 180-200 g were obtained from the Department of Zoology of the University of Yaounde I. They were housed in clean cages with five rats per cage and maintained under standard laboratory conditions (room temperature with dark/light cycle $12 / 12 \mathrm{~h}$ ) for three days and fed with a standard diet and normal tap water.

\section{Oral glucose tolerance test on normoglycemic rats}

Oral glucose tolerance test (OGTT) was performed on thirty (30) male albino Wistar rats. The rats were acclimated for 7 days and divided into six groups with each group consisting of five rats. The rats were fasted overnight for $18 \mathrm{~h}$ but had access to water and their glycemia was taken at the start of the test $\left(t_{0}\right)$. Half an hour before the administration of the standard glucose solution ( $2 \mathrm{~g} / \mathrm{kg}$ of body weight (BW), each group of rats received either water, a hypoglycemic drug (glibenclamide $4 \mathrm{mg} / \mathrm{kg} \mathrm{BW}$ ), or the extract ( $400 \mathrm{mg} / \mathrm{kg} \mathrm{BW}$ ), except for the negative control group, which received water. The treatment lasted for $2 \mathrm{~h}$ and their glycemia was measured at 30-min time intervals $(30,60,90,120$ min) using a glucometer [15].

\section{Inhibitory effects of extracts on starch and sucrose digestion in normoglycemic rats}

The OGTT procedure described above with slight modifications was used. Modifications included $2 \mathrm{~g} / \mathrm{kg}$ BW of sucrose and $1 \mathrm{~g} / \mathrm{kg} \mathrm{BW}$ of starch, used to replace glucose. Acarbose ( $3 \mathrm{mg} / \mathrm{kg} \mathrm{BW}$ ) was used as the reference drug. Blood glucose was measured at $30,60,90$, and $120 \mathrm{~min}$.

\section{Statistical analysis}

Results were expressed as mean \pm standard deviation. Statistical analyses were done using the Statistical Package for Social Science (SPSS) software, version 17.0, for Windows. One-way analysis of variance (ANOVA) between groups was done with LSD (least significant difference) as post hoc test to compare the in vivo results. Significant differences were detected at $95 \%$ confidence interval.

\section{Results}

\section{Polyphenolic compounds and antioxidant activities of HEE of $N$. fruticans seed}

The polyphenolic compounds and total antioxidant capacity of the Nypa seed mesocarp extracts are shown Table 1. Total polyphenol content was $42.87 \mathrm{mg}$ EG/g DM and flavonoid content $19 \mu \mathrm{g}$ EG/g DM. The total antioxidant capacity of the extract $(5 \mathrm{mg} / \mathrm{mL})$ was $0.47 \mathrm{mg}$ EAA/g DM.

\begin{tabular}{|c|c|c|c|}
\hline & $\begin{array}{c}\text { Total } \\
\text { polyphenols } \\
\text { (mg EG/g of } \\
\text { DM) }\end{array}$ & $\begin{array}{c}\text { Flavonoids }(\mu \mathbf{g} \\
\text { EG/g of DM) }\end{array}$ & $\begin{array}{c}\text { Total } \\
\text { antioxidant } \\
\text { capacity (mg } \\
\text { EA/g of DM) }\end{array}$ \\
\hline $\begin{array}{c}\text { HEE } \\
\text { of } \boldsymbol{N} \text {. fruticans }\end{array}$ & $42.87 \pm 0.76$ & $19 \pm 0.5$ & $0.47 \pm 0.01$ \\
\hline
\end{tabular}

DM: dry mesocarp and the result as mean \pm standard deviation; EA: equivalent ascorbic acid; EG: equivalent gallic acid.

Table 1: Total polyphenol and flavonoid contents and total antioxidant capacity of HEE of $N$. fruticans seed

$\mathrm{DPPH}$ and $\mathrm{ABTS}^{+}$free radical-scavenging ability were examined at five different concentrations $(2,4,6,8$, and $10 \mathrm{mg} / \mathrm{mL})$ and the results expressed as scavenging activity is presented in Figure 1. All extract concentrations expressed strong scavenging capacity, which increased with concentration, ranging from $42.13 \%$ to $72.50 \%$ for DPPH and from $49.34 \%$ to $89.90 \%$ for ABTS. Half scavenging concentrations $\left(\mathrm{SC}_{50}\right)$, derived through logarithmic regression analysis from the graph, were found to be $2.96 \mathrm{mg} / \mathrm{mL}$ for DPPH and $2.21 \mathrm{mg} / \mathrm{mL}$ for ABTS Thus, the extract scavenging capacity of $\mathrm{ABTS}^{+}$cation was stronger than that of the DPPH free radical.

Postprandial glucose-lowering activities of HEE of $N$. fruticans seed in vitro assay

Glucose-binding capacity expressed as the percentage of glucose reduction of the extract is shown in Figure 2. Glucose binding was found to increase with extract concentration and ranged from 9.19 $(0.5 \mathrm{mg} / \mathrm{mL})$ to $57.17 \%$ for $(16 \mathrm{mg} / \mathrm{mL})$

\section{Effect of HEE on glucose absorption}

The ability of the extract to regulate postprandial hyperglycemia following oral administration in normoglycemic rats is presented in Table 2. Administration after $30 \mathrm{~min}\left(t_{30}\right)$ of glucose loading $(10 \mathrm{mM})$ in the test groups resulted in glycemia peak in the positive group higher than the peak obtained with the negative group throughout the experiment. In the group receiving extracts, glycemia $(68.60 \mathrm{mg} /$ $\mathrm{mL}$ ) at $30 \mathrm{~min}$ after glucose loading was lower than that of the positive control group $(103.71 \mathrm{mg} / \mathrm{mL})$. However, glycemia considerably reduced to the same level in the two groups at the 180th $\min (59.80$ and $59.85 \mathrm{mg} / \mathrm{mL}$, respectively). The extract group also expressed a

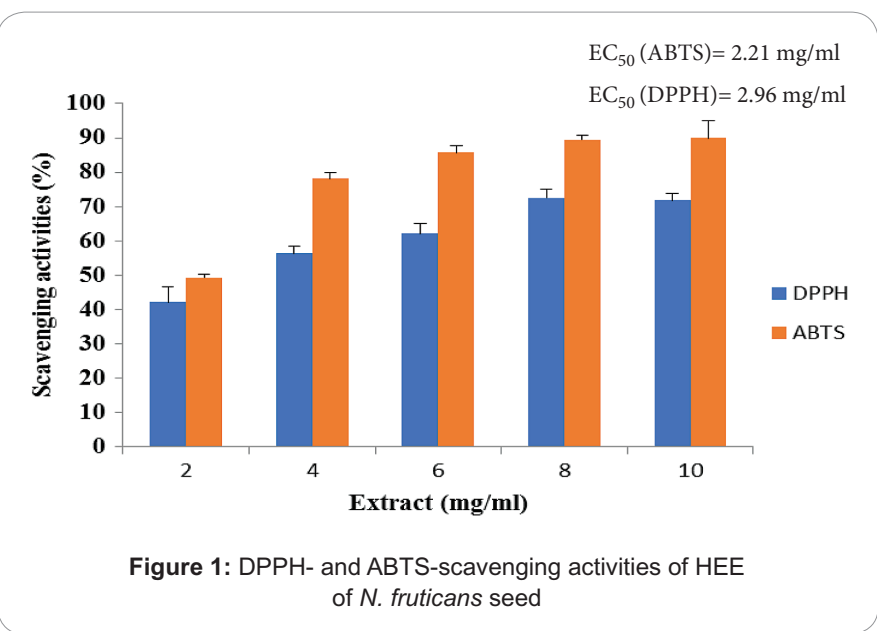


Citation: Martin F, Boris NS, Kengne SR, Chia TE, Guy TN, et al. (2017) Antioxidant and Postprandial Glucose-lowering Potential of the Hydroethanolic Extract of Nypa fruticans Seed Mesocarp. Biol Med (Aligarh) 9: 407. doi: 10.4172/0974-8369.1000407

Page 4 of 6

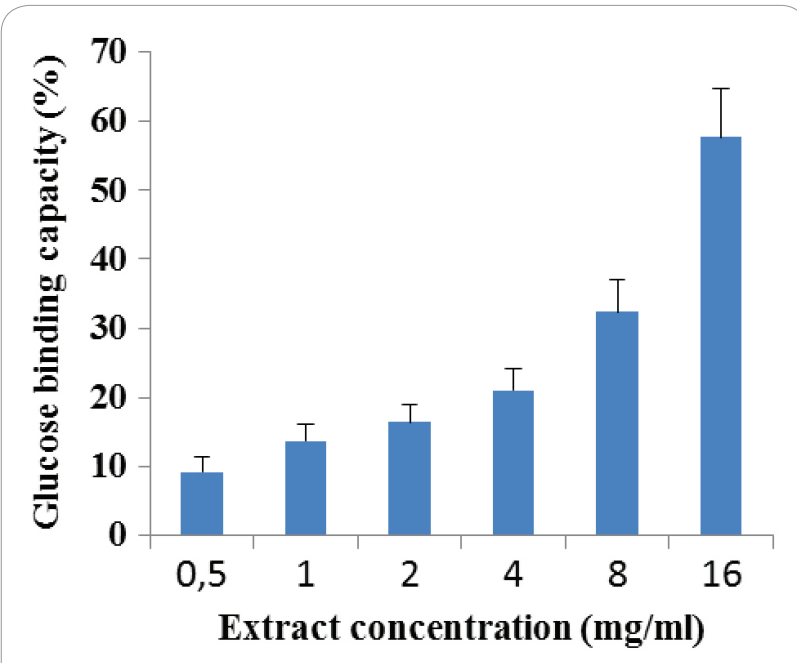

Figure 2: Glucose-binding capacity of HEE of $N$. fruticans seed

lower glycemic levels at $t_{30}$ compared to the reference (glibenclamide) group $(90.8 \mathrm{mg} / \mathrm{mL})$. Thereafter, glycemia significantly reduced to the 180 th $\mathrm{min}$ in the reference group $(20 \mathrm{mg} / \mathrm{mL})$ compared to the extract group.

\section{Effect of HEE on starch digestion and absorption}

The variation in glycemia following the administration of starch digestion is presented in Table 3. The positive control expressed the highest glycemic values compared to the negative group throughout the experiment. At $30 \mathrm{~min}$, glycemia was highest in the group receiving extract $(95.4 \mathrm{mg} / \mathrm{mL})$ compared to the positive control $(76.14 \mathrm{mg} / \mathrm{mL})$ and the reference (acarbose) $(75.6 \mathrm{mg} / \mathrm{mL})$ groups. However, at $t_{180}$, glycemic variation had reduced in all the groups below the initial glycemic state.

\section{Effect of HEE on sucrose digestion and absorption}

Glycemic variation from sucrose digestion in rats following the oral administration of the extract and control preparations is presented in Table 4 . The positive control group had the highest postprandial glucose level compared to the negative control group throughout the study. The group receiving extract also had the lower plasma glucose compared to the positive group throughout the study period. In the same way, the extract group expressed lower plasma glucose level compared to the reference group throughout the study. The glycemia was $73.58 \mathrm{mg} / \mathrm{mL}$ for the extract group against 90.14 and $82.80 \mathrm{mg} / \mathrm{mL}$ for the positive and extract groups, respectively.

\section{Discussion}

One of the major problems in the management of DM is the control of postprandial hyperglycemia, which depends on digestion and absorption of carbohydrates and stimulation of incretins [16], which increase the release of insulin by beta-pancreatic cells. Hyperglycemia is highly correlated to the increase of pro-oxidants like free radicals, which cause oxidative stress, proven to be implicated in the development and complication of diabetes. Screening of bioactive compounds, which can act both on postprandial glycemia and on oxidative stress, could be a better alternative in the management of diabetes. This study revealed that HEE of $N$. fruticans seed mesocarp possesses high total polyphenol content and total antioxidant capacity in a concentration-dependent

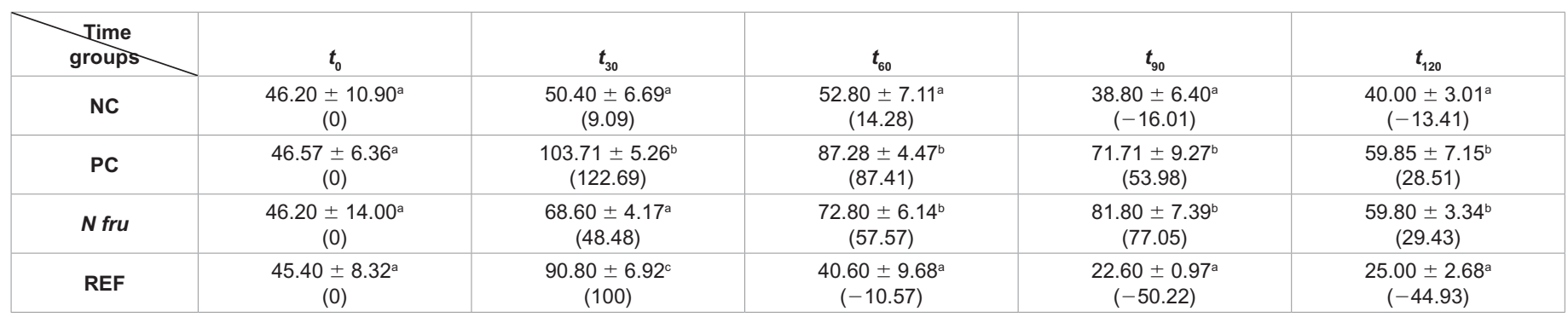

NC: negative control; PC: positive control; REF: reference; and $N$ fru: $N$. fruticans. The values in parentheses are the percentage variation; results are expressed as mean in glycemia \pm standard error of mean.

Values having differences indices had significant differences at $5 \%$.

Table 2: Effect of HEE of $N$. fruticans seed on glucose tolerance

\begin{tabular}{|c|c|c|c|c|}
\hline Groups & $t_{0}$ & $t_{30}$ & $t_{60}$ & $t_{180}$ \\
\hline NC & $\begin{array}{c}66.40 \pm 6.22^{a} \\
(0)\end{array}$ & $\begin{array}{c}58.80 \pm 11.04^{a} \\
(-11.44)\end{array}$ & $\begin{array}{c}58.00 \pm 12.11^{a} \\
(-12.65)\end{array}$ & $\begin{array}{c}51.20 \pm 10.24^{a} \\
(-22.89)\end{array}$ \\
\hline PC & $\begin{array}{c}59.71 \pm 8.15^{\mathrm{a}} \\
(0)\end{array}$ & $\begin{array}{c}76.14 \pm 7.16^{b} \\
(27.51)\end{array}$ & $\begin{array}{c}63.85 \pm 4.41^{\mathrm{b}} \\
(6.93)\end{array}$ & $\begin{array}{c}54.00 \pm 3.80^{\mathrm{ab}} \\
(-9.56)\end{array}$ \\
\hline$N$ fru & $\begin{array}{c}67.80 \pm 6.21^{\mathrm{a}} \\
(0)\end{array}$ & $\begin{array}{c}95.40 \pm 9.47^{\circ} \\
(40.7)\end{array}$ & $\begin{array}{c}78.00 \pm 3.17^{c} \\
(15.04)\end{array}$ & $\begin{array}{c}61.60 \pm 2.59^{\mathrm{bc}} \\
(-9.14)\end{array}$ \\
\hline REF & $\begin{array}{c}66.20 \pm 7.27^{\mathrm{a}} \\
(0)\end{array}$ & $\begin{array}{c}75.60 \pm 11.64^{b} \\
(14.19)\end{array}$ & $\begin{array}{c}77.00 \pm 13.84^{\circ} \\
(16.31)\end{array}$ & $\begin{array}{c}64.40 \pm 3.69^{\circ} \\
(-2.71)\end{array}$ \\
\hline
\end{tabular}

NC: negative control; PC: positive control; REF: Reference; and N fru: $N$. fruticans. The values in parentheses are the percentage variation; results are expressed as mean in glycemia \pm standard error of mean.

Values having differences indices had significant differences at $5 \%$.

Table 3: Effect of HEE of $N$. fruticans seed on starch digestion

\begin{tabular}{|c|c|c|c|c|}
\hline Groups & $\boldsymbol{t}_{\mathbf{0}}$ & $\boldsymbol{t}_{30}$ & $\boldsymbol{t}_{60}$ & $\boldsymbol{t}_{180}$ \\
\hline NC & $\begin{array}{c}66.40 \pm 6.22^{\mathrm{a}} \\
(0)\end{array}$ & $\begin{array}{c}58.80 \pm 11.04^{\mathrm{a}} \\
(-11.44)\end{array}$ & $\begin{array}{c}58.00 \pm 12.11^{\mathrm{a}} \\
(-12.65)\end{array}$ & $\begin{array}{c}51.20 \pm 10.24^{\mathrm{a}} \\
(-22.89)\end{array}$ \\
\hline PC & $\begin{array}{c}59.71 \pm 8.15^{\mathrm{a}} \\
(0)\end{array}$ & $\begin{array}{c}76.14 \pm 7.16^{\mathrm{b}} \\
(27.51)\end{array}$ & $\begin{array}{c}63.85 \pm 4.41^{\mathrm{b}} \\
(6.93)\end{array}$ & $\begin{array}{c}54.00 \pm 3.80^{\mathrm{a}, \mathrm{b}} \\
(-9.56)\end{array}$ \\
\hline N fru & $\begin{array}{c}67.80 \pm 6.21^{\mathrm{a}} \\
(0)\end{array}$ & $\begin{array}{c}95.40 \pm 9.47^{\mathrm{c}} \\
(40.7)\end{array}$ & $\begin{array}{c}78.00 \pm 3.17^{\mathrm{c}} \\
(15.04)\end{array}$ & $\begin{array}{c}61.60 \pm 2.59^{\mathrm{b}, \mathrm{c}} \\
(-9.14)\end{array}$ \\
\hline REF & $\begin{array}{c}66.20 \pm 7.27^{\mathrm{a}} \\
(0)\end{array}$ & $\begin{array}{c}75.60 \pm 11.64^{\mathrm{b}} \\
(14.19)\end{array}$ & $\begin{array}{c}77.00 \pm 13.84^{\mathrm{c}} \\
(16.31)\end{array}$ & $\begin{array}{c}64.40 \pm 3.69^{\mathrm{c}} \\
(-2.71)\end{array}$ \\
\hline
\end{tabular}

NC: negative control; PC: positive control; REF: Reference, and $N$ fru: $N$. fruticans. The values in parentheses are the percentage variation and the results expressed as mean in glycemia \pm standard error of mean. Values having differences indices had significant differences at $5 \%$.

Table 4: Effect of HEE of $N$. fruticans seed on sucrose digestion 
manner (Table 1). These results are indicators of a possible antioxidant capacity of HEE and demonstrate their ability to reduce Mo (VI) to Mo (V). Phenolic compounds are secondary metabolites reported to exert physiological effects [17]. These results in accordance with many other studies [18], could also be explained by the fact that related polyphenols and many flavonoids contribute significantly to the phosphomolybdenum reduction activity through the transfer of electrons as showed by Khan et al. [19].

An exposure of HEE with nonbiologically generated free radicals DPPH and ABTS, which are synthetic radicals commonly used to evaluate the scavenging activity of plant extract, has shown a scavenging activity on DPPH and ABTS radicals (Figure 1). This result is in accordance with those of Nagendra et al. [20], who showed that the extracts of ripe and unripe endosperm of $N$. fruticans possess the DPPHand ABTS-scavenging abilities. The DPPH radical has been widely used to evaluate free radical-scavenging capacity of antioxidants. It contains an odd electron, which is responsible for the violet color. When DPPH accepts an electron donated by an antioxidant compound, the DPPH is decolorized to yellow [21]. Also, the blue/green ABTS radical cation is generated by the oxidation of ABTS with potassium persulfate; its reduction in the presence of hydrogen-donating antioxidants is measured spectrophotometrically at $745 \mathrm{~nm}$. The scavenging effects observed can be attributed to the presence of flavonoids in HEE extract, due to their redox properties. Flavonoids play an important role in absorbing and neutralizing free radicals, by donating hydrogens or electrons [22].

Phenolic compounds also exhibit strong hypoglycemic effects through several mechanisms including inhibition of carbohydrate digestive enzymes, regulation of pancreatic function, and glycosylation [23]. The in vitro and in vivo studies on the modulatory effects of hydroethanolic extract on glucose absorption and carbohydrate digestion revealed that the extract possesses the ability to scavenge glucose (Figure 2) through glycosylation, although such glycosylation may instead improve other therapeutic actions of the extract [24]. In fact, phenolic compounds, such as flavonoids, found in HEE can directly react with glucose molecules to form a flavonoid-glucose complex, thereby reducing the amount of free glucose. The glycosylated glucose molecule therefore would be unable to cross cell membranes, hence the reduction of glucose absorption due to conformational structures and chemical and physical changes affecting biochemical functions [24]. Given that in vitro studies only show the direct interaction between extract and substrate, the postprandial glucose-lowering potential of the of the $N$. fruticans seed mesocarp was done under physiological conditions so that many other factors could be involved. The oral glucose tolerance test conducted to evaluate the effects of HEE on pancreatic beta-cells function revealed their lowering potential on postprandial glycemia after glucose and sucrose administration (Tables 2 and 4). This result is in accordance with the findings of Wang et al. [25] and Hasan et al. [8] and can be attributed to polyphenols, which may suppress glucose release from the liver and improve glucose uptake in peripheral tissues by modulating intracellular signaling [23]. Hasan et al. [8] also demonstrated that methanolic leaves and stem extracts of $N$. fruticans decrease glycemia at 60 and $120 \mathrm{~min}$ after glucose loading. Similar results were also found by Yusoff et al. [26] on the aqueous extract of $N$. fruticans Wurmb after glucose and sucrose or starch loading. However, the hydroethanolic extract of $N$. fruticans seed mesocarp showed an increase of postprandial glycemia after starch administration (Table 3); it may be due to the high content of carbohydrates present in the seed mesocarp [6], proving that HEE probably has no inhibitory effect on amylase activity. Several mechanisms could explain the results observed and the hyperglycemia activity of the hydroethanolic extract of $N$. fruticans nuts. These include inhibition of sucrose activity, inhibition of intestinal glucose absorption, stimulation of insulin secretion by beta pancreatic cells, and stimulation of glucose utilization [18].

Flavonoids or phenolic compounds have been associated with inhibition of alpha-glucosidase [27]. The hydroethanolic extract of $N$. fruticans could be ameliorating postprandial hyperglycemia by competing with glucose for the binding site on glucose transporters, thus delaying the process of glucose absorption. However, it is important to note that if the inhibition mechanism could be noncompetitive, this could prevent the presence or absence of substrate from affecting the binding of the inhibitor to the enzyme, resulting in less interaction with meals [28,29]. Hassimotto et al. [30] reported that one of the intestinal glucose uptake mechanisms influenced by a flavonoids probably involved SGLT1. Glycemic decrease observed with HEE may also occur due to the stimulatory effect on beta cells to promote insulin release given that insulin stimulates an intracellular glycogen deposition and glucose utilization [31]. Furthermore, HEE can reduce PPG by stimulating early insulin release after sucrose administration that increases and more reduction of glucagon secretion, resulting in regularization of glucose homeostasis [16,32].

\section{Conclusions}

$N$. fruticans seed mesocarp is a rich source of dietary polyphenols with high antioxidant capacity and radical-scavenging capacity. The hydroethanolic extract of seed mesocarp has in addition a glucophage activity and inhibitory effect on the last phase of carbohydrate digestion. Therefore, consumption of $N$. fruticans seed mesocarp, already an eating habit in Asia and Africa, should be encouraged and extended to other continents. In combination with other existing dietary measures to manage diabetes, control strategies against postprandial hyperglycemia and its related complications would probably be more efficient.

\section{Conflict of Interests}

None declared.

\section{Authors' Contributions}

All authors contributed equally to this study.

\section{References}

1. van de Weijer T, Sparks LM, Phielix E, Meex RC, van Herpen NA, et al. (2013) Relationships between mitochondrial function and metabolic flexibility in type 2 diabetes mellitus. PLoS One 8: e51648.

2. WHO (World Health Organization) (2016) Global report on diabetes. WHO Library Cataloguing-in-Publication Data, 1-6.

3. Alam A, Zaidul M, Ghafoor K, Sahena F, Hakim M, et al. (2017) In vitro antioxidant and, alpha-glucosidase inhibitory activities and comprehensive metabolite profiling of methanol extract and its fractions from Clinacanthus nutans. Complement Altern Med 17(181): 1-10.

4. Erejuwa O (2012) Management of diabetes mellitus: could simultaneous targeting of hyperglycemia and oxidative stress be a better panacea? Int J Mol Sci 13(3): 2965-2972.

5. Rahmatullah M, Sadeak SM, Bacharetal SC (2010) Brine shrimp toxicity study of different Bangladeshi medicinal plants. Adv Nat Appl Sci 1(4): 163-173.

6. Osabor VN, Egbung GE, Okafor PC (2008) Chemical profile of Nypa fruiticans from Cross River Estuary, south eastern Nigeria. Pak J Nutr 7(1): 146-150. 
Citation: Martin F, Boris NS, Kengne SR, Chia TE, Guy TN, et al. (2017) Antioxidant and Postprandial Glucose-lowering Potential of the Hydroethanolic Extract of Nypa fruticans Seed Mesocarp. Biol Med (Aligarh) 9: 407. doi: 10.4172/0974-8369.1000407

Page 6 of 6

7. Aziz A, Jack R (2015) Total phenolic content and antioxidant activity in Nypa fruticans extracts. JSSM 10(1): 87-91.

8. Hasan R, Wahid M, Asish K, Shahnaz R, Rownak J, et al. (2011) Antihyperglycemic and antinociceptive activity of methanol leaf and stem extract of Nypa fruticans wurmb. Pak J Pharm Sci 24(4): 485-488.

9. Singleton V, Rossi J (1965) Colorimetry of total phenolics with phosphomolydicphosphotungstic acid reagents. Am J Enol Vitic 16: 144-158.

10. Aiyegoro OA, Okoh Al (2010) Preliminary phytochemical screening and In vitro antioxidant activities of the aqueous extract of Helichrysum longifolium DC. BMC Complement Altern Med 10: 21.

11. Prieto P, Pineda M, Aguilar M (1999) Spectrophotometric quantitation of antioxidant capacity through the formation of a phosphomolybdenum complex: specific application to the determination of vitamin E. Anal Biochem 269 337-341.

12. Katalinie V, Milos M, Modiun D, Musi I, Boban M (2003) Antioxidant effectiveness of selected wines in comparison with (+)- catechin. Food Chem 86: $593-600$.

13. Re R, Pellegrini N, Preoteggente A, Pannala A, Yang M, et al. (1999) Antioxidant activity applying an improved $A B T S$ radical cation decolorization assay. Free Radic Biol Med 9(10): 121-137.

14. Kebieche M (2009) Activité biochimique des extraits flavonoïdiques de la plante Ranunculus repens $L$ : effet sur le diabète expérimental et l'hépatotoxicité induite par l'Epirubicine. Thèse de doctorat, Université Mentouri Constantine $1-143$.

15. Trinder $P$ (1959) Determination of glucose in blood using glucose oxidase with an alternative acceptor. Ann Clin Biochem 6: 24-27.

16. John G (2013) Pathogenesis and management of postprandial hyperglycemia: role of incretin-based therapies. Int J Gen Med 6: 877-895.

17. Govindappa MA (2015) Review on role of plant(s) extracts and its phytochemicals for the management of diabetes. J Diabetes Metab 6(7): 1-38.

18. Munir K, Sruti C, Feng G, Michael J (2013) Mechanisms for food polyphenols to ameliorate insulin resistance and endothelial dysfunction: therapeutic implications for diabetes and its cardiovascular complications. Am J Physio Endocrinol Metab 305(6): E679-E686.

19. Khan RA, Khan MR, Sahreen S, Ahmed M (2012) Assessment of flavonoids contents and in vitro antioxidant activity of Launaea procumbens. Chem Cent $J$ 6: 43
20. Nagendra P, Azrina A, Bao Y, Amin I, Kin W, et al. (2013) Phytochemicals and antioxidant capacity from Nypa fruticans Wurmb. Fruit 2013: 1-10

21. Joginder S, Akansha R, Pardeep K, Pooja S, Surekha (2015) Antimicrobia and free radical scavenging activity of selective medicinal plants combination. World J Pharm Pharm Sci 4(3): 1202-1216.

22. Angappan M, Karuppaiah J (2015) Screening of phytochemical and in vitro antioxidant property of n-miracle (polyherbal formulation). World J Pharm Res 4(6): 1702-1717

23. Kim Y, Jennifer B, Clifton PM (2016) Polyphenols and glycemic control. Nutrients $8(1): 17$

24. Shayli V, Waleed M, Pegah V, Pavla S, Istvan T (2016) Glycosylation, an effective synthetic strategy to improve the bioavailability of therapeutic peptides. Chem Sci 7: 2492-2500.

25. Wang X, Tian J, Jiang J, Li L, Ying X, et al. (2014) Effects of green tea or green tea extract on insulin sensitivity and glycaemic control in populations at risk of type 2 diabetes mellitus: a systematic review and meta-analysis of randomised controlled trials. J Hum Nutr Diet 27: 501-512.

26. Yusoff N, Ahmad M, Al-Hindi B, Widyawati T, Yam V, et al. (2015) Aqueous extract of Nypa fruticans Wurmb. Vinegar alleviates postprandial hyperglycemia in normoglycemic rats. Nutrients 7: 7012-7026.

27. Oboh G, Ademiluyi AO, Akinyemi AJ, Henle T, Saliu JA et al. (2012) Inhibitory effect of polyphenol-rich extracts of jute leaf (Corchorus olitorius) on key enzyme linked to type 2 diabetes (a-amylase and hypertension (angiotensin converting) in vitro. J Funct Foods 4: 450

28. Shihabudeen S, Priscilla DH, Thirumurugan KT (2011) Cinnamon extract inhibits a-glucosidase activity and dampens postprandial glucose excursion in diabetic rats. Nutr Metab 8: 46

29. Mayur B, Sandesh S, Shruti S, Sung-Yum S (2010) Antioxidant and a-glucosidase inhibitory properties of carpesium abrotanoides L. J Med Plant Res 4: 1547.

30. Hassimotto NM, Genovese MI, Lajolo FM (2008) Absorption and metabolism of cyanidin-3-glucoside and cyanidin-3-rutinoside extracted from wild murberry (Morus nigra L.) in rats. Nutr Res 28: 198-207.

31. Jensen J, O'Rahilly S (2017) AMPK is required for exercise to enhance insulin sensitivity in skeletal muscles. Mol Metab 6(4): 315-316.

32. Woerle H, Szoke E, Meyer C, Dostou JM, Wittlin SD, et al. (2006) Mechanisms for abnormal postprandial glucose metabolism in type 2 diabetes. Am J Physio Endocrinol Metab 290(1): E67-E77. 